\title{
Front Matter: Volume 10828
}

, "Front Matter: Volume 10828," Proc. SPIE 10828, Third International Workshop on Pattern Recognition, 1082801 (2 August 2018); doi: $10.1117 / 12.2507036$

SPIE Event: Third International Workshop on Pattern Recognition, 2018, Jinan, SPIE. China 


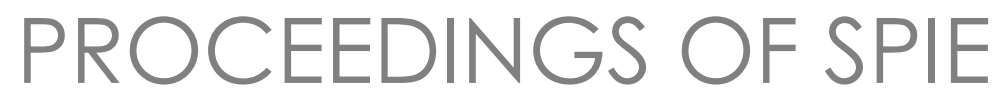

\title{
Third International Workshop on Pattern Recognition
}

\author{
Xudong Jiang \\ Zhenxiang Chen \\ Guojian Chen \\ Editors
}

26-28 May 2018

Jinan, China

Organized by

University of Jinan (China)

Sponsored by

Hainan University (China)

Shandong University (China)

Ocean University of China (China)

Published by

SPIE 
The papers in this volume were part of the technical conference cited on the cover and title page. Papers were selected and subject to review by the editors and conference program committee. Some conference presentations may not be available for publication. Additional papers and presentation recordings may be available online in the SPIE Digital Library at SPIEDigitalLibrary.org.

The papers reflect the work and thoughts of the authors and are published herein as submitted. The publisher is not responsible for the validity of the information or for any outcomes resulting from reliance thereon.

Please use the following format to cite material from these proceedings:

Author(s), "Title of Paper," in Third International Workshop on Pattern Recognition, edited by Xudong Jiang, Zhenxiang Chen, Guojian Chen, Proceedings of SPIE Vol. 10828 (SPIE, Bellingham, WA, 2018) Seven-digit Article CID Number.

ISSN: 0277-786X

ISSN: 1996-756X (electronic)

ISBN: 9781510622685

ISBN: 9781510622692 (electronic)

Published by

SPIE

P.O. Box 10, Bellingham, Washington 98227-0010 USA

Telephone +1 3606763290 (Pacific Time) · Fax +1 3606471445

SPIE.org

Copyright @ 2018 , Society of Photo-Optical Instrumentation Engineers.

Copying of material in this book for internal or personal use, or for the internal or personal use of specific clients, beyond the fair use provisions granted by the U.S. Copyright Law is authorized by SPIE subject to payment of copying fees. The Transactional Reporting Service base fee for this volume is $\$ 18.00$ per article (or portion thereof), which should be paid directly to the Copyright Clearance Center (CCC), 222 Rosewood Drive, Danvers, MA 01923. Payment may also be made electronically through CCC Online at copyright.com. Other copying for republication, resale, advertising or promotion, or any form of systematic or multiple reproduction of any material in this book is prohibited except with permission in writing from the publisher. The CCC fee code is 0277$786 \mathrm{X} / 18 / \$ 18.00$.

Printed in the United States of America.

Publication of record for individual papers is online in the SPIE Digital Library.

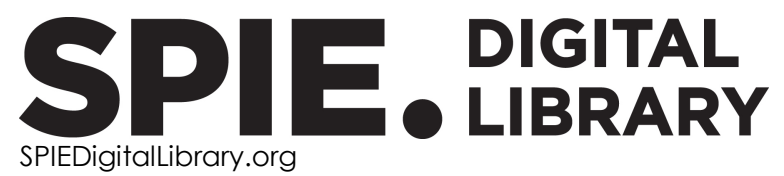

Paper Numbering: Proceedings of SPIE follow an e-First publication model. A unique citation identifier (CID) number is assigned to each article at the time of publication. Utilization of CIDs allows articles to be fully citable as soon as they are published online, and connects the same identifier to all online and print versions of the publication. SPIE uses a seven-digit CID article numbering system structured as follows:

- The first five digits correspond to the SPIE volume number.

- The last two digits indicate publication order within the volume using a Base 36 numbering system employing both numerals and letters. These two-number sets start with 00, 01, 02, 03, 04, 05, 06, 07, 08, 09, OA, OB ... 0Z, followed by 10-1Z, 20-2Z, etc. The CID Number appears on each page of the manuscript. 


\title{
Contents
}

\author{
vii Authors \\ ix Conference Committee \\ xiii Introduction
}

SESSION $1 \quad$ PATTERN RECOGNITION

1082802 Classification of handwritten Japanese hiragana characters of 71 categories attached with sound marks by using pattern augmentation for deep learning [10828-50]

1082803 Radar micro-doppler signature analysis and its application on gait recognition [10828-12]

$1082804 \quad$ Fingerprint identification based on neural network for large fingerprint database [10828-18]

1082805 An abnormal telephone identification model based on ensemble algorithm [10828-20]

1082806 Microcontroller-based face recognition using combinations of morphing algorithms of BeierNeely, Delaunay Triangulation and Alpha Blending [10828-59]

1082807 Recognizing emotions in chinese text using dictionary and ensemble of classifiers [10828-33]

1082808 A method of automatic recognition for answer sheet [10828-28]

1082809 Button location and recognition method for elevator based on artificial mark and geometric transformation [10828-46]

\section{SESSION 2 TARGET DETECTION}

10828 OA 3D-DETNet: a single stage video-based vehicle detector [10828-57]

$10828 \mathrm{OB}$ Outlier detection algorithm based on robust component analysis [10828-64]

10828 OC Global contrast saliency detection of images with small scale structure suppression [10828-48]

10828 OD An extension of BING to high IOU threshold [10828-44]

10828 OE Robust vanishing point detection based on block wise weighted soft voting scheme [10828-49] 
10828 OF Fast infrared image segmentation method based on 2D OTSU and particle swarm optimization [10828-29]

10828 OG Aesthetic QR code generation with background contrast enhancement and user interaction [10828-61]

$10828 \mathrm{OH} \quad$ Glandular cavity segmentation based on local correntropy-based K-means (LCK) clustering and morphological operations [10828-52]

10828 ol Statistical multi-scale laws' texture energy for texture segmentation [10828-31]

$10828 \mathrm{OJ}$ The denoising semi-coupled dictionary learning for retina image super-resolution [10828-36]

\section{SESSION 4 IMAGE DETECTION TECHNOLOGY AND APPLICATION}

10828 OK Indirect Gaussian kernel parameter optimization for one-class SVM in fault detection [10828-15]

$10828 \mathrm{OL} \quad$ A computer aided diagnosis system for lung cancer detection using support vector machine [10828-56]

$108280 \mathrm{M}$ Learning to rank-based abnormal phone analysis in environment of telecommunication big data [10828-19]

10828 ON DroidDetector: a traffic-based platform to detect android malware using machine learning [10828-39]

$1082800 \quad$ Escherichia coli and Enterococcus faecalis growth detection device in ice using impedance microbiology and image processing technique [10828-51]

10828 OP Oil spills detection by spreading attention along gestalt cues [10828-4]

$108280 Q \quad$ Design of integrated quality detect system for saw blades based on LabVIEW [10828-30]

10828 OR Detection of zero degree belt loss in radial tire based on multiscale Gabor transform [10828-45]

10828 OS Surface defects detection of paper dish based on Mask R-CNN [10828-66]

10828 OT Determination of jeepney engine condition based on smoke emission analysis using carbon monoxide and carbon dioxide gas sensors with color-based segmentation using L*a*b color space [10828-60]

10828 OU Spectral-spatial hyperspectral image classification based on extended training set [10828-69]

10828 OV A self-adaptive subtraction algorithm for dynamic background video [10828-54] 
10828 OW Special faster-RCNN for multi-objects detection [10828-14]

10828 OX An automatic facial beautification method for video post-processing [10828-24]

10828 oy Crowd counting system by facial recognition using Histogram of Oriented Gradients, Completed Local Binary Pattern, Gray-Level Co-Occurrence Matrix and Unmanned Aerial Vehicle [10828-58]

$10828 \mathrm{OZ}$ A CNN-based probability hypothesis density filter for multitarget tracking [10828-5]

$1082810 \quad$ Research on position calibration method of temperature image of pool based on image processing technology [10828-10]

1082811 Grayscale difference sensitivity of human eyes on LCD screen [10828-38]

1082812 Fractional amplitude of low-frequency fluctuation and degree centrality in autistic children: a resting-state fMRI study [10828-6]

$1082813 \quad$ Rapid image retrieval with binary hash codes based on deep learning [10828-62]

$1082814 \quad$ Fast scene layout estimation via deep hashing [10828-22]

1082815 A similarity learning for fine-grained images based on the Mahalanobis metric and the kernel method [10828-2]

SESSION 6 SIGNAL ANALYSIS AND PROCESSING

$1082816 \quad$ Fine scale estimation for correlation filter tracking [10828-21]

1082817 Attribute reduction based on improved information entropy [10828-16]

1082818 Classification of ECG Arrhythmia using symbolic dynamics through fuzzy clustering neural network [10828-25]

$1082819 \quad$ Ensemble empirical mode decomposition applied to long-term solar time series analysis [10828-67]

108281 A A fast CUM-m-Capon algorithm for DOA estimation based on fourth-order cumulant [10828-9]

10828 1B Music genre classification using a hierarchical long short term memory (LSTM) model [10828-7]

10828 1C Indexing and classifying snore characteristics using Support Vector Machine and integrated signal processing algorithm [10828-53] 


\section{SESSION 7 COMPUTER SCIENCE AND ENGINEERING}

10828 1D A genetic algorithm-based approach for class-imbalanced learning [10828-8]

$10828 \mathrm{IE}$ Ideal solutions of TOPSIS based on vague sets and their application to landmark preference [10828-27]

$10828 \mathrm{IF} \quad$ Research on opinion spreading based on military hierarchical network [10828-17]

10828 IG Target regression tracking based on convolutional neural network [10828-23]

$10828 \mathrm{1H} \quad$ Hadoop-based analysis model of network public opinion and its implementation [10828-68]

$1082811 \quad$ A rough-set based measurement for the membership degree of fuzzy C-means algorithm [10828-26]

$108281 \mathrm{~J}$ Short-term power load forecasting based on the PSO-RVR model [10828-40]

10828 1K Design for omni-directional mobile wheelchair control system based on brain computer interface [10828-13] 


\section{Authors}

Numbers in the index correspond to the last two digits of the seven-digit citation identifier (CID) article numbering system used in Proceedings of SPIE. The first five digits reflect the volume number. Base 36 numbering is employed for the last two digits and indicates the order of articles within the volume. Numbers start with 00, 01, 02, 03, 04, 05, 06, 07, 08, 09, OA, OB...0Z, followed by 10-1Z, 20-2Z, etc.

\begin{tabular}{|c|c|}
\hline Agus, Jordaniel C., ОТ & He, Liping, $0 G$ \\
\hline Ai, Yanyong, 07 & He, Xue, $1 E$ \\
\hline An, Jianmei, 19 & Hou, Qingtao, OR \\
\hline An, Qinghao, 09 & Hu, Libin, OW \\
\hline An, Zhiyong, OV & Huo, Kai, $1 \mathrm{~A}$ \\
\hline Aruna Kumar, S. V., 18 & Ji, Hanran, OV, $1 \mathrm{~J}$ \\
\hline Balbin, Jessie R., 06, 00, 0T, OY, IC & $\mathrm{Ji}, \mathrm{Ke}, \mathrm{OM}$ \\
\hline Cai, Yunfang, 19 & Ji, Kei, 05 \\
\hline Calma, Ross Junior S., 1C & Ji, Lixin, OB \\
\hline Chao, Kaikai, 1 A & Jiang, Bo, OG, OX \\
\hline Chen, Shuying, OV & Jiang, Weidong, IA \\
\hline Chen, Feng, OA & Jiang, Wenxue, 10 \\
\hline Chen, Rui, 08 & Jiang, Xudong, 03 \\
\hline Chen, Zhenxiang, 07, ON & Katigbak, Kzandra H., 00 \\
\hline Cheng, Wei, OQ, 10 & Li, Changli, OU \\
\hline Chui, Ka Long, 1B & $\mathrm{Li}$, Chenming, $\mathrm{OZ}$ \\
\hline Cuevas, Nicole Marie Antonette A., 1C & Li, Hanxi, 14 \\
\hline Deng, GuangWei, 13 & Li, Jinjiang, $1 \mathrm{~J}$ \\
\hline Deng, Qianqian, OP & Li, Jinping, 08, 09, 0l, OR, 11 \\
\hline Dong, Jiwen, OJ & Li, Shaomei, OB, 16 \\
\hline Dong, Junyu, OS & Li, Suichan, OA \\
\hline Dong, Shangyan, ID & Li, Tao, 13 \\
\hline Dong, Ting, 15 & Li, Wenlong, $0 Q, 10$ \\
\hline Dou, Hao, OP & Liang, Baohua, 17 \\
\hline Dou, Yimin, 11 & Liang, Yankuan, $\mathrm{OZ}$ \\
\hline Emirzade, Erkan, OL & Lin, Lijian, OG \\
\hline Fan, Hui, iJ & Ling, Weilin, OC \\
\hline Fan, Jiancong, 11 & Liu, Haiyan, $1 \mathrm{~F}$ \\
\hline Fan, Xiang, $1 \mathrm{G}$ & Liu, Jian, OM \\
\hline Fan, Xue, OE & Liu, Jun, OS \\
\hline Feng, Guang, OJ & Liu, Peiyu, $1 \mathrm{H}$ \\
\hline Feng, Zhimin, 15 & Liu, Sijiang, OG, OX \\
\hline Feng, Zhiquan, $\mathrm{OE}$ & Liu, Song-Tao, OF \\
\hline Fernandez, Kaira Emi D., OY & Liu, Yun, 17 \\
\hline Fu, Zisheng, 15 & Lomotan, Bradly L., 00 \\
\hline Gao, Chao, OB, 16 & Lu, Jiaxing, $1 \mathrm{~K}$ \\
\hline Gao, Haichao, OK & Lu, Zhang, IF \\
\hline Gao, Nan, 13 & Luo, Wenbing, 14 \\
\hline Gao, Nuo, 1K & Ma, Hui, OS \\
\hline Gao, Peng, OP & Ma, Kun, 05, OM \\
\hline Gao, Ying, OS & $M a, Q i, 1 G$ \\
\hline Garcia, Ramon G., OY & Ma, Qingzeng, 10 \\
\hline Ge, Hailong, 0Q, 10 & Ma, Xinqiang, $O Q$ \\
\hline Golosinda, Nicolo Paolo G., OY & Ma, Yingjun, $\mathrm{OH}$ \\
\hline Guan, Junling, 12 & Magpayo, Karyl Denise G., OY \\
\hline Guo, Canzhang, OD & Magwili, Glenn V., OT \\
\hline Halili, Mark P., 06 & Malonga, Richard Anthony T., OT \\
\hline Harish, B.S., 18 & Manalo, Jazzleen S., OT \\
\hline Hassan, Muhammad Umair, $\mathrm{OH}, \mathrm{ON}$ & Meng, Qingfang, 12 \\
\hline
\end{tabular}


Miao, Bo, 12

Montealegre, Earl P., 06

$\mathrm{Niu}$, Dongmei, $\mathrm{OH}$

Niu, Sijie, OJ

Omori, Yuki, 02

Pang, Ying, 07

Pang, Zengzhi, OR

Paningbatan, James Erwin $\mathrm{V}$., $1 \mathrm{C}$

Peng, Juan, 04

Pontino, Angela A., 06

Qi, Lin, OS

Qi, Yi, 19

Qin, Xukun, OS

Ramirez, Glazy P., 06

Ren, Jianfeng, 03

Ren, Yuan, 10

Reyes, Erick John B., ОT

Rollon, Areej Gabrielle R., 00

Roopa, C. K., 18

Ruan, Fei, 17

Sejera, Marianne M., 06

Şekeroğlu, Boran, OL

Shen, Jingya, ON

Shi, Jianjie, 09

Shima, Yoshihiro, 02

Sun, Runyuan, 05, 0M

Tang, Chun Pui, 1B

Tangonan, Hazel Wynne D., 00

Tian, Jinwen, OP

Tian, Wensha, OX

Tu, XiaoHan, 13

Velasco, Robee Jasper B., OY

Ventura, Michael Angelo B., 1C

Vergara, Ernesto M., 00, 1C

Wang, Fei, $1 \mathrm{H}$

Wang, Jingwen, 10

Wang, Liping, $\mathrm{OH}$

Wang, Mingwen, 14

Wang, Ninghua, 15

Wang, Qingyun, OU

Wang, Shanshan, 07, ON

Wang, Teng, OW

Wang, Weifang, OJ

Wang, Wenguang, $\mathrm{OZ}$

Wang, Wentao, 10

Wang, Xianping, 19

Wang, Xuelong, OS

Wang, Yanchuan, OB, 16

Wang, Zhan, OF

Wang, Zhen, OF

Wang, Zhenhao, 11

Wang, Zhicheng, 04

Wardhani, Mega Kusuma, 0 I

Wei, Bo, 1E

Wei, Changzhi, OW, $1 F$

Wong, Kin Hong, 1B

Wu, Linyan, $1 \mathrm{~K}$

Wu, Xiang, 08

Wu, Yongcheng, 1D

Xia, Yingjie, 08
Xiao, Yingchao, OK

Xie, Bo, $1 G$

Xu, Cheng, 13

Xu, Qian, 16

$X U, T a O, O E$

Yan, Yongjie, OK

Yang, Haoyu, IE

Yang, Li, 04

Yang, Xiaohui, OE

Yang, Xinghai, OW, $1 \mathrm{~F}$

Yin, Xiaohu, $1 \mathrm{~F}$

Yu, Chengrong, OX

Yu, Hongtao, 16

Yu, Xiangru, 08, 0l, 11

YU, Ying Kin, 1B

Yuan, Genji, $1 \mathrm{~J}$

Yuan, Yahan, 05

Zai, Weiwei, $1 \mathrm{~K}$

Zeng, Zhiliang, 1B

Zhan, Yinwei, OC, OD

Zhang, JiaHui, OV

Zhang, Hongwei, 04, $1 \mathrm{G}$

Zhang, Xiaoyu, 1E

Zhang, Xinyu, IA

Zhang, Yan, $1 \mathrm{~J}$

Zhang, Yulin, 12

Zhang, Zhiyi, $1 \mathrm{~F}$

Zheng, Cha, OB, 16

Zheng, Xiunan, OR

Zhi, Hongxin, 16

Zhou, Yifeng, OX

Zhu, Bin, 1G

Zhu, Yi, 14

Zhu, Yuhui, ON

Zhu, Zhenfang, $1 \mathrm{H}$

Zou, Xinyi, OG

Zuo, Yongyan, 19 


\title{
Conference Committee
}

\author{
International Advisory Committee \\ Pedro Furtado, Universidade de Coimbra (Portugal) \\ Honorary General Chair \\ Yuehui Chen, University of Jinan (China) \\ Conference Chairs
}

Xudong Jiang, Nanyang Technological University (Singapore)

Jiwen Dong, University of Jinan (China)

Conference Co-chairs

Yilong Yin, Shandong University (China)

Yongquan Liang, Shandong University of Science and Technology (China)

Zhenxiang Chen, University of Jinan (China)

Program Chairs

Jinping Li, University of Jinan (China)

Giovanni Maria Farinella, Università degli Studi di Catania (Italy)

Kin Hong Wong, The Chinese University of Hong Kong (Hong Kong)

Kin Choong Yow, Gwangju Institute of Science and Technology (Korea)

Program Co-chairs

Xinshun Xu, Shandong University (China)

Junyu Dong, Ocean University of China (China)

Aythami Morales, Universidad Autonoma de Madrid (Spain)

Local Organizing Chair

Shouning Qu, University of Jinan (China) 
Local Organizing Vice-chairs

Dong Wang, University of Jinan (China)

Sijie Niu, University of Jinan (China)

Publication Chair

Guojian Chen, Hainan University (China)

Organization Committees

Shiyuan Han, University of Jinan (China)

Kun Ma, University of Jinan (China)

Chuan Zhao, University of Jinan (China)

Xiaohui Yang, University of Jinan (China)

Jinglan Tian, University of Jinan (China)

Local Technical Committee

Zhiquan Feng, University of Jinan (China)

Xiuyang Zhao, University of Jinan (China)

Lin Wang, University of Jinan (China)

Yuan Zhang, University of Jinan (China)

Lizhi Peng, University of Jinan (China)

Qinfang Meng, University of Jinan (China)

Technical Committee

Arnold Paglinawan, Mapúa University (Philippines)

Yinwei Zhan, Guangdong University of Technology (China)

Jessie R. Balbin, Mapúa University (Philippines)

Julius T. Sese, Mapúa University (Philippines)

Chen-long Guo, Guilin University of Aerospace Technology (China)

Jianmei An, Chongqing University of Arts and Sciences (China)

Boran Şekeroğlu, Near East University (Turkey)

Sijiang Liu, Nanjing University of Posts and Telecommunications (China)

Baohua Liang, Chaohu University (China)

Songtao Liu, Dalian Naval Academy (China)

Nacera Benamrane, University of Sciences and Technology

Mohamed Boudiaf Oran USTO (Algeria)

Hany Mansour, Military Technical College (Egypt)

Emre Sumer, Baskent University (Turkey)

Mohamed Arezki Mellal, M'Hamed Bougara University

(Algeria) 
Xuebo Zhang, Science and Technology on Underwater Acoustic Antagonizing Laboratory (China)

Shuai Zhao, Big Switch Networks Inc (United States)

Yinglei Song, Jiangsu University of Science and Technology (China)

Jingjing Xiao, Xinqiao Hospital of Third Military Medical University (China)

Mohammad Reza Khosravi, Shiraz University of Technology (Iran)

Changli Li, Hohai University (China)

Amik Singh, WhatsApp Inc. (United States)

Filippo Neri, Università degli Studi di Napoli Federico II (Italy)

Jibin Yang, PLA University of Science and Technology (China)

Deepak Ghimire, Korea Electronics Technology Institute (Korea, Republic of)

Ngaiming Kwok, The University of New South Wales (Australia)

Wei Jia, HeFei University of Technology (China)

Arti Khaparde, Maharashtra Institute of Technology (India)

Gaurav Bhatnagar, University of Windsor (Canada)

Linhua Deng, Chinese Academy of Sciences (China)

Osama Halabi, Qatar University (Qatar)

Mahesha Kapurubandara, Sri Lanka Institute of Information Technology (Sri Lanka)

Bo Jiang, Nanjing University of Posts and Telecommunications (China)

Fang Wang, Nanchang Institute of Technology (China)

Qiu Chen, Kogakuin University (Japan)

Beom-Seok Oh, Nanyang Technological University (Singapore)

Touhid Bhuyian, Daffodil International University (Bangladesh)

T. Hanumanth Reddy, RYMEC Engineering College (India)

Young-Woong Ko, Hallym University (Korea)

Bok-Min Goi, Universiti Tunku Abdul Rahman (Malaysia)

Reinhard Klette, Auckland University of Technology (New Zealand)

Andrew B.J. Teoh, Yonsei University (South Korea)

Lei Meng, Nanyang Technological University (Singapore)

Manish Khare, Dhirubhai Ambani Institute of Information and

Communication Technology(DA-IICT) (India)

Zhe Jin, Universiti Tunku Abdul Rahman (Malaysia)

Ying-Hao Yu, National Chung Cheng University (Taiwan)

B. S. Harish, JSS Science \& Technology University (India)

Weili Zhang, eBay Inc. (United States)

Session Chairs

$1 \quad$ Machine Learning and Data Engineering

Yoshihiro Shima, Meisei University (Japan) 
2 Neural Network Theory and Application

Kun Ma, University of Jinan (China)

3 Image and Signal Processing

Yuan Zhang, University of Jinan (China)

$4 \quad$ Computer and Electrical Engineering

Lizhi Peng, University of Jinan (China)

5 Pattern Recognition and Target Detection

Aythami Morales, Universidad Autonoma de Madrid (Spain)

$6 \quad$ Image Analysis and Methods

Yunxia Liu, University of Jinan (China) 


\section{Introduction}

In recent years, pattern recognition has become a hot research branch thanks to the recent advances of machine learning driven by big data. In light of the fastpaced advancements in pattern recognition taking place all over the world, it is of great interest to keep an eye on the state-of-the-art research and development and to facilitate collaboration in multidisciplinary research areas. With this end in view, it was a great pleasure for me to invite you to participate in the 2018 International Workshop on Pattern Recognition which was held 26-28 May 2018 in Jinan, China.

The aim of the conference was to address and deliberate on the latest technical status and recent trends in the research, developments and applications of pattern recognition. This conference was designed with the view of providing an opportunity for scientists, engineers, industrialists, students and other professionals from all over the world to interact and exchange their new ideas and research outcomes for future collaboration.

This year, IWPR solicited 98 submitted papers from various countries all over the world. The proceedings of IWPR 2018 contains 55 selected papers from the conference that have been presented at the conference either orally or via poster sessions. They provide the up-to-date, comprehensive and worldwide state-of-theart knowledge and techniques in this field. Each contributed paper was rigorously peer-reviewed by international reviewers who were drawn from the organizing and advisory committee members and external reviewers in related fields from all over the world. The proceedings cover the specific areas as follows: pattern recognition, target detection, image transformation and analysis, image detection technology and application, image processing and application, signal analysis and processing, and computer science and engineering.

On behalf of the organizing committee, we would like to express our heartful gratitude to all the reviewers for their great professionalism and efforts. And thank all the participants and sponsors for their valuable contributions and support of IWPR 2018.

\section{Xudong Jiang}


Proc. of SPIE Vol. 10828 1082801-14 Downloaded From: https://www.spiedigitallibrary.org/conference-proceedings-of-spie on 26 Apr 2023
Terms of Use: https://www.spiedigitallibrary.org/terms-of-use 